\title{
URBAN RAIN GAUGE SITING SELECTION BASED ON GIS-MULTICRITERIA ANALYSIS
}

\author{
Yanli Fu ${ }^{\mathrm{a}}$, Changfeng Jing ${ }^{\mathrm{a}, *}$, Mingyi $\mathrm{Du}^{\mathrm{a}}$ \\ ${ }^{\text {a }}$ School of Geomatics and Urban Spatial Information, Beijing University of Civil Engineering and Architecture, \\ 100044 Beijing, China - diecheyanruyu@gmail.com,jingcf@ bucea.edu.cn, dumingyi@bucea.edu.cn
}

\author{
Commission II, WG II/3
}

KEY WORDS: Rain Gauge, Site Selection, Multicriteria, Spatial Analysis, Buffer Analysis

\begin{abstract}
:
With the increasingly rapid growth of urbanization and climate change, urban rainfall monitoring as well as urban waterlogging has widely been paid attention. In the light of conventional siting selection methods do not take into consideration of geographic surroundings and spatial-temporal scale for the urban rain gauge site selection, this paper primarily aims at finding the appropriate siting selection rules and methods for rain gauge in urban area. Additionally, for optimization gauge location, a spatial decision support system (DSS) aided by geographical information system (GIS) has been developed. In terms of a series of criteria, the rain gauge optimal site-search problem can be addressed by a multicriteria decision analysis (MCDA). A series of spatial analytical techniques are required for MCDA to identify the prospective sites. With the platform of GIS, using spatial kernel density analysis can reflect the population density; GIS buffer analysis is used to optimize the location with the rain gauge signal transmission character. Experiment results show that the rules and the proposed method are proper for the rain gauge site selection in urban areas, which is significant for the siting selection of urban hydrological facilities and infrastructure, such as water gauge.
\end{abstract}

\section{INTRODUCTION}

Rainfall is regarded as an available variable for the domain in ecology, health and disease, climatology, meteorology, hydrology and so forth (Dyras et al., 2003).In view of the heavy rain strong influence on the metropolis in many aspects, such as traffic, environment, personal and social safety as well as the municipal infrastructure construction, it is of great significance to generate homologous strategies for the normal and safe operation in cities. That is to say, a proper method should be sought to further address the impact of urban rainfall monitoring by design dense rain gauge network which can achieve accurately predicting rainfall.

A common approach in meteorology is to combine rainfall estimation with rain gauge-radar (García-Pintado et al., 2009; Haberlandt, 2007). This method can get a more precise value, which owns some important reference values for water resource management, analysis of spatial-temporal characters in drought and flood disaster management. And the accuracy of precipitation is closely associated with the rain gauge density and distribution. Ground-automation rainfall gauge and meteorological radar are the major ways to obtain precipitation, while rainfall gauge is widely applied due to some advantages, such as high-precision, real-time and so on. Limited to materials and surrounding complexity, it is difficult to deploy highdensity rainfall gauge network. Hence, rainfall gauge site selection analysis becomes a research focus (Bastin et al., 1984; Pardo-Igúzquiza, 1998; Shepherd et al., 2004). Mishra classified research methods for network evaluation into six following as below: statistical methods, information theory-based methods, user survey approach, physiographic components, sampling strategies, and hybrid method (Mishra and Paulin, 2009). Shaghaghian considered the conditions of rain gauge deployment, combining geostatistics and multivariate analysis techniques for studying rainfall gauges optimal deployment in plain regions with 25,000 $\mathrm{km}^{2}$ (Shaghaghian and Abedini, 2013); Anil Kumar Kar proposed that using multi-criteria decision analysis and clustering techniques designed a rain gauge network to forecast flood in lower Mahanadi river basin, India (Kar et al., 2015); Basing on entropy, Su did corresponding research on gauge siting selection optimization aiming at Shihmen Reservoir watershed in central Taiwan ( $\mathrm{Su}$ and You, 2014); however, algorithm efficiency is a bit low.

Present research on rain gauge site selection is primarily for global region or drainage basin. However, there are few researches for small urban area. Furthermore, recorded rainfall data and grounding coverage (such as residential areas, signal interference sources) were not taken into consideration for siting of rain gauges.

Focused on the above issues, this paper tends to analyse and explore deployment of rain gauges in urban small area. Therefore, several siting rules and guidelines were discussed and a multicriteria decision (MCD) approach based on GIS was developed to locate optimal sites with aforementioned rules. A multicriteria analysis model for the optimization siting is applied to urban rain gauges siting under the urban complex circumstance.

\section{THE STUDY AREA AND DATA}

The study is conducted Xicheng District located in Beijing (Figure 1), which is a small-scale city region with approximately $50 \mathrm{~km}^{2}$. Xicheng District is the political center, commercial zones and tourism distributing area in one of the important urban area. It is located in the North China Plain which has a little climatic diversity. In view of slope, the area is

\footnotetext{
${ }^{*}$ Changfeng Jing
} 
gentle, namely, elevation variation is relatively small, the paper takes into no consideration of terrain influence. This paper chooses residential buildings, roads, substations, high-voltage wires as the primary constraint data sources, garbage houses and public toilets as the initial data. All the preparation is performed within ArcGIS 10.2 software.

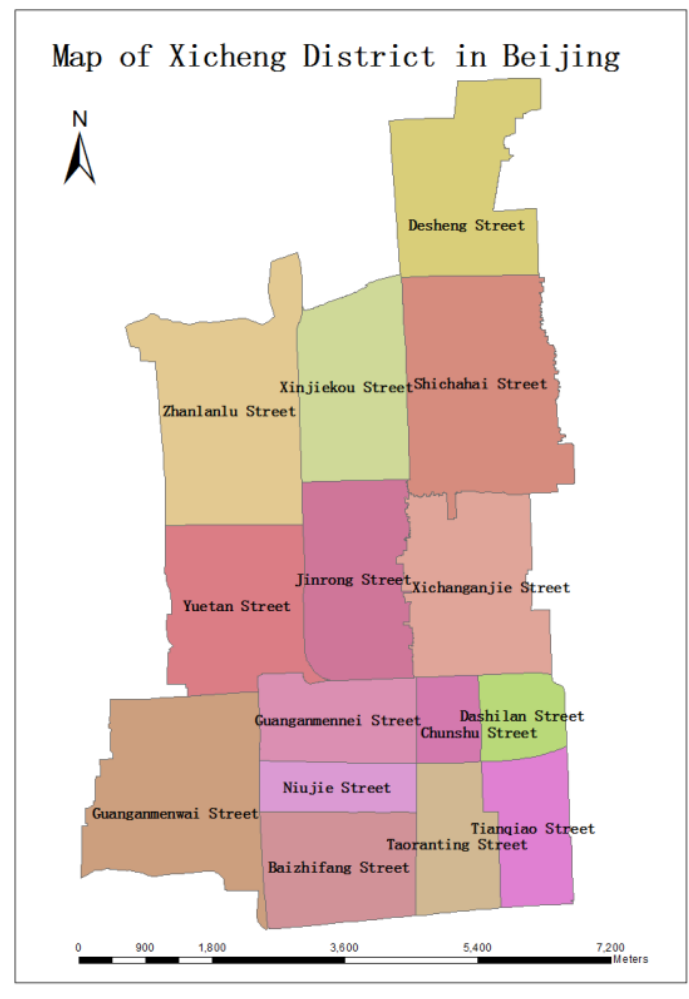

Figure 1 . The study area

\section{GIS-BASED MCDA FOR RAIN GAUGE SITING IN URBAN AREA}

\subsection{Spatial Analysis}

GIS is widely used in land suitability, urban planning, natural risk management, hydrology and water resources, and so on. Spatial analysis has played a central role with its powerful dynamic represent technology and analysis methods in above fields. Increasingly, many fields integrated spatial analysis method to resolve practical problems, such as fire service deployment in Los Angeles County (Church and Li, 2015); population density estimation (Sakai et al., 2016); the least and most polluted areas on the Olt River, in Romania (Borza and Petrescu, 2016); resource supply allocation (Comber et al., 2015); environmental and geographical influences on epidemiology of acromegaly in Brazil (Luciana Ansaneli et al., 2015); On account of the complexity of these spatial problems, the use of spatial analysis is indispensable.

While GIS, as an ideal tool for performing spatial searches based on map data, is useful, there are some limitations to process multiple criteria and conflicting objectives (CARVER, 1991). It is also limited in integrating geographical information with subjective values/priorities imposed by the decision maker (Leake and Malczewski, 2000). GIS are used in conjunction with other systems and methods, such as the method for multicriteria decision making (MCDM). Synergistic effect is obviously generated by combining the powerful tool-GIS to the above method for rain-gauge site selection. In this paper, the method for MCDM is essential in site selection with kernel density estimation, buffer analysis and geostatistical analysis.

\subsection{Kernel Density Estimation}

Kernel density estimation (KDE) is a tool to calculate density of the given features in the specific neighbourhood around and then reflect the spatial patterns and the distribution density of the study objectives. In the light of KDE outweighing other density estimation methods (such as Quadrat analysis) in expressing the above spatial characters and considering the regional impact of the first law of geography (Wenhao and Tinghua, 2015), the density estimation method is adopted in this research. Its input parameters are just restricted to line events or point events, namely, excluding polygon features. The density analysis studies the aggregation condition in terms of the input feature data.

$\mathrm{KDE}$ is a non-parametric estimate method based local information defined by windows (also called kernels) to estimate density of specified features of geographic phenomena (Shi, 2010). The method could be applied to, for instance, road accident hotspots (Anderson, 2009), health and disease (Kloog et al., 2009), electricity consumption (Arora and Taylor, 2014), and other fields. Bandwidth and cell size are the two major parameters influencing the KDE. The output of $\mathrm{KDE}$ is constituted in the form of raster with a grid of cells. Obviously, the cell size stands for the cluster happening in fact. The chosen size is also a trade-off among the sample size, computation time, and the information to retain (Lalita et al., 2015).With respect to another parameter of bandwidth, it determines the extent of the study area.

\subsection{Buffer Analysis}

Buffer analysis is one of the most important and fundamental spatial analysis methods to address the problem of proximity, and is used very frequently and widely. This method can offer scientific basis to different work requirements.

Buffer is to identify the degree of influence on a certain geographical entity or spatial objectives to surrounding surface features, and then build a band-shaped region with a certain width. As to the method of buffer analysis, it automatically establishes buffer zones with a certain distance so that it can analyse the impact on neighbouring objects in the buffer zone by the study features, according to the spatial characteristics of features (point, line, and polygon) (Yiqiang et al., 2007), such as point-shaped precipitation data, line-shaped roads, and polygon-shaped residential areas. There are two ways to generate buffer zones, on the basis of two different formats of data, raster and vector. The vector method is widely used, having a time, and is comparatively mature. Nevertheless, raster data quantity and the operation scale are very large. As long as geographical entities can impact on the surrounding regions, this analysis method is available. Additionally, the spatial information data structured process also requires to recursively perform buffer analysis operations (Xiangnan, 2005). Vector buffer analysis is employed in this paper.

\subsection{Multicriteria Decision-Making Methods}

Multicriteria analysis, as a decision-making method, introduced into the field of decision, was during the 1960s (Fang et al., 2014). The research on goal programming conducted by Charnes and Cooper, the method for ELECTRE proposed by Roy in 1968, as well, are the representatives. In 1972, Cochrane and Zeleny organized the first International Conference on multicriteria decision making at the University of South 
Carolina, which is universally reckoned as the landmark of initial development of multicriteria decision making. Since the 1970s, MCDM has dramatically advanced, and the theory and practice in the field has got great breakthrough (Geosciences, 2014)

Multi-Criteria Decision Analysis (MCDA) takes significant account of modern decision science. MCDA supports to structure decision problems, or to design, evaluate, prioritize some alternative decisions. It is usually used to solve a variety of site selection problems due to its convenience, efficiency, reasonability, as well. And the basic aim of the approach is to investigate a wealth of choice possibilities according to multiple criteria and conflicting objectives to select the "best" alternative from the number of feasible choice-alternatives (Voogd, 1984). The six main elements of MCDA are as following: aim, decision-maker, criteria, decision-making options, environment state and scores. Among them, criteria are the basis of decision and the standard of judgement; evaluation scores are the foundation of various analyses.

Figure 2 shows the frame of MCDA method:

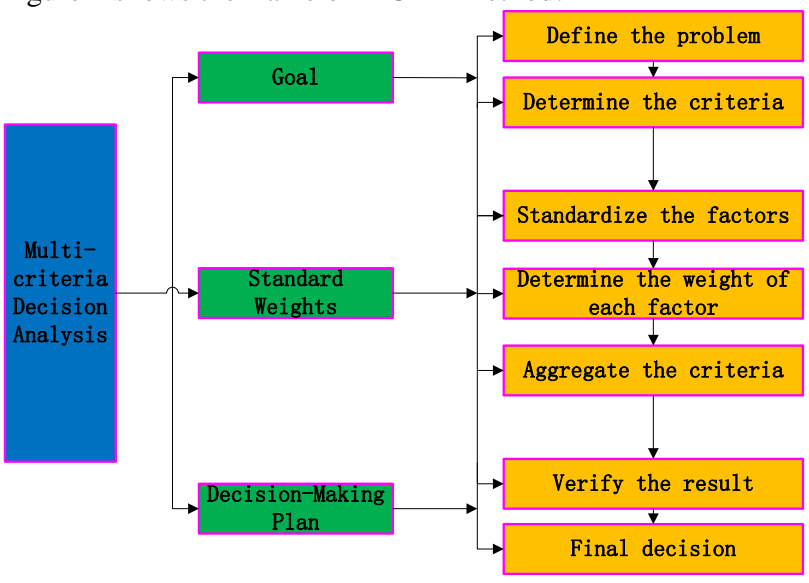

Figure 2. Frame diagram of MCDA

\subsubsection{Rain Gauge Site Selection Criteria and Evaluation}

During the period of decision, a set of complex and scientific evaluation index system should be established for decision objectives, which is the fundamental work for evaluation. Especially in multicriteria problems, it is essential to consider that whether one criterion to be more important than another. Numbers are the major way to weigh this relative importance. They are often called weight, which are designed to different criteria. Herein, the determination of evaluation criteria for each corresponding factor is an important work, due to its relative to the final decision's rationality and feasibility and the final choice.

Generally speaking, the so-called criteria are a set of guidelines or requirements used as basis for a decision. Criteria can be of two kinds: factors and constraints. A factor is a kind of criteria, enhanced or detracted from the specific alternatives under given application. A constraint provides some limitations to the alternatives.

This paper aims at small-scale city area to determine site selection conditions as following:

a) The "ideal" rain gauge location should be located in an open and flat area, with a considerable distance from objects, such as buildings, meanwhile, trees will not deflect the entry of wind-blow rain into the gauge for the consideration of consistent and accurate measurements;

b) Due to the urban operation monitoring requirements, the deployment of rain gauges are supposed to satisfy the principle of "the key monitoring, the uniform distribution", such as high-density resident buildings and scenic spots;

c) As GPRS is the main way to transform information, the signal should be strong enough for the normal communication flow;

d) And the selected position may avoid strong electromagnetic interference areas, such as substations and high-voltage wires;

Based on the above guidelines, a series of criteria input parameters are developed. The input parameters for initial consideration are roads (major, minor), buildings (residential buildings, business buildings), precipitation data (requirement for the key monitoring), high-voltage wires and substations. It is worth to mention that Xicheng District in Beijing belongs to a small-scale region, so terrain influence is not considered in this paper.

The evaluation criteria (according to Code for Design of Urban Road Engineering, Regulations on the Protection of Power Facilities in China) and criteria scores follow as below (the range of influence is extended to an extent):

\begin{tabular}{lccccc}
\hline Factor Score & $\mathbf{1}$ & $\mathbf{2}$ & $\mathbf{3}$ & $\mathbf{4}$ & $\mathbf{5}$ \\
\hline $\begin{array}{l}\text { Annual } \\
\text { Precipitation(mm) }\end{array}$ & $75-82$ & $82.1-87$ & $87.1-93$ & $93.1-104$ & $104.1-120$ \\
$\begin{array}{l}\text { Distance to } \\
\text { Road(m) }\end{array}$ & 20 & 30 & 40 & 50 & 60 \\
$\begin{array}{l}\text { Distance to } \\
\text { Substation(m) }\end{array}$ & 10 & 20 & 30 & 40 & 50 \\
$\begin{array}{l}\text { Distance to High- } \\
\text { voltage Wire(m) }\end{array}$ & 10 & 20 & 30 & 40 & 50 \\
\hline
\end{tabular}

Table 1. The factor criteria setting

In view of the different importance of the above criteria, the order follows as below: the interpolation result, high-voltage wire, substation and road. At the same time, five to one express the respective important rank, the number five shows the influence of the criteria is the most important, on the contrary, number one is the least important factor comparatively.

\subsection{GIS-MCDA Solution for Rain-Gauge Site Selection}

Despite the fact that multicriteria decision support system and GIS can respectively address some simple problems independently, the combination of GIS and MCDA provides better solutions to solve numerous complicated problems. Multicriteria decision-making analysis and GIS are two unique research fields, beneficial in their application mutually. On the one hand, MCDA offers rich aggregating techniques and program structure to decision-makers, and design, evaluate, optimize alternative choice, while one of the most important applications of GIS is the display and analysis of data to support the process of environmental decision-making ( $R$, 1999). In addition, the involved evaluation criteria and weights help decision-maker obtain the most appropriate one. On the other hand, GIS and MCDA have their own characteristics to complement each other, namely, GIS has an important role to play in managing data, spatial analysis, visualizing system platform and the mode of decision support. Then, gradual integration of GIS and MCDA forms so-called mode, GISMCDA. At the most rudimentary level, GIS-MCDA can be thought of as a process that transforms and combines 
geographical data and value judgements (the preferences of decision-maker) to obtain information for decision making (Malczewski, 2007).

Figure 3 is the structure of integrated GIS and MCDA model in rain-gauge site selection.

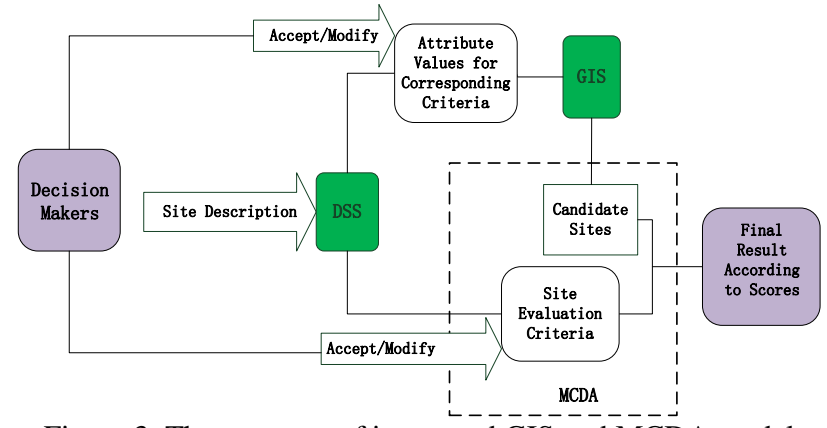

Figure 3. The structure of integrated GIS and MCDA model

\section{RESULTS AND DISCUSSION}

Figure 4 shows the workflow of siting rain gauge based on MCDA, which is used in Xicheng District of Beijing in China.

$$
\begin{aligned}
& \text { Initial Position: Garbage } \\
& \text { Houses and Public Toilets }
\end{aligned}
$$

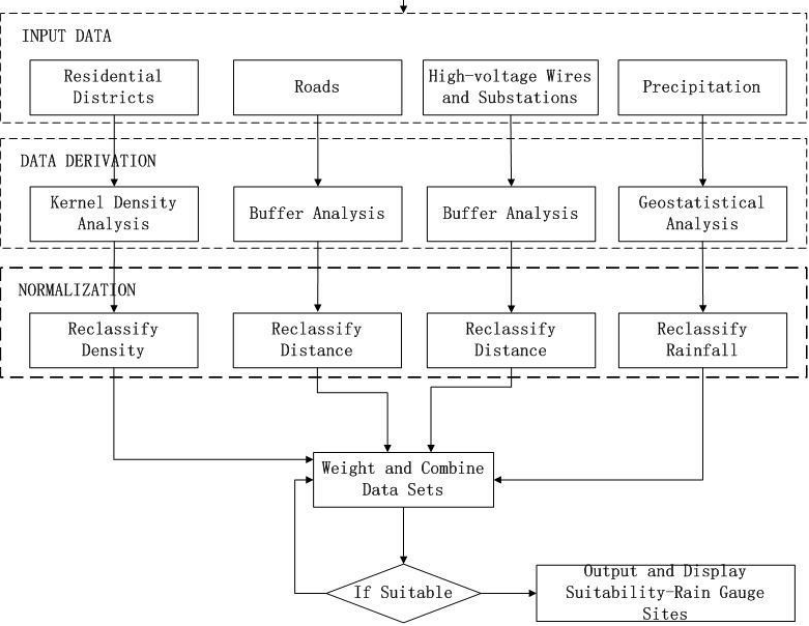

Figure 4. Workflow of rain gauge site selection

On the basis of the aforementioned rules and guidelines, the garbage houses and public toilets (Figure 5(a)) of Xicheng District in China are chosen as the initial positions for rain gauges, other input parameters includes roads (Figure 5(b)), residential areas (Figure 5(c)), substations, high-voltage wires (Figure 5(d)), and precipitation. Under the support of GIS platform, the input data will be addressed via spatial analyses, such as kernel density (Figure 6(a)), buffer analysis (Figure 6(b),(c)), Inversed Distance Weighted as well, and the output results (density, distance, and rainfall) can be classified into five ranks respectively.

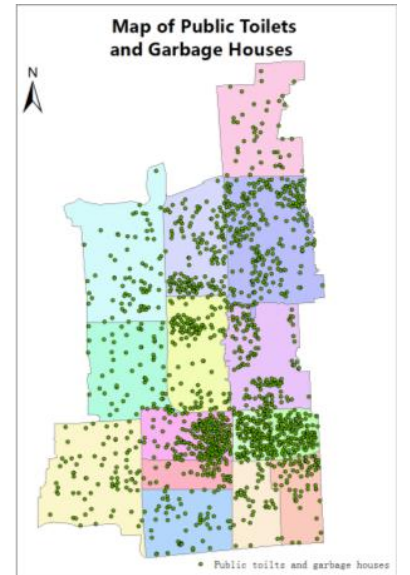

(a)

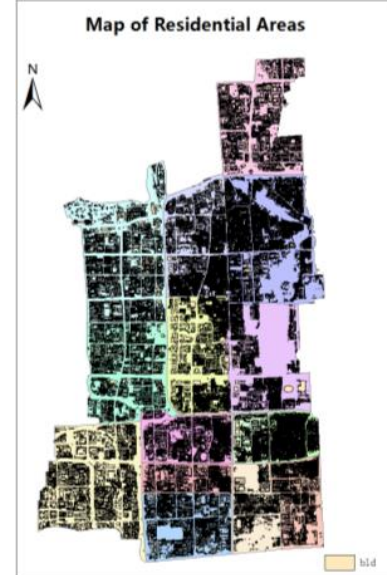

(c)

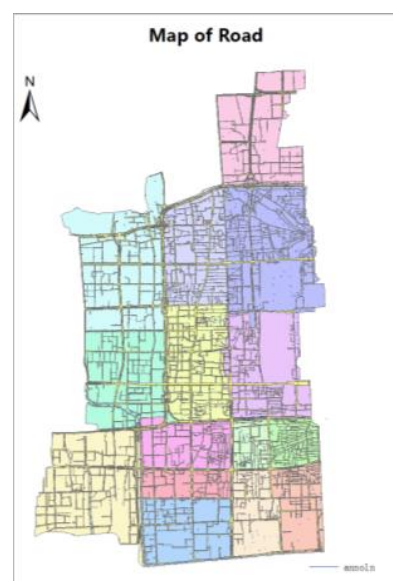

(b)

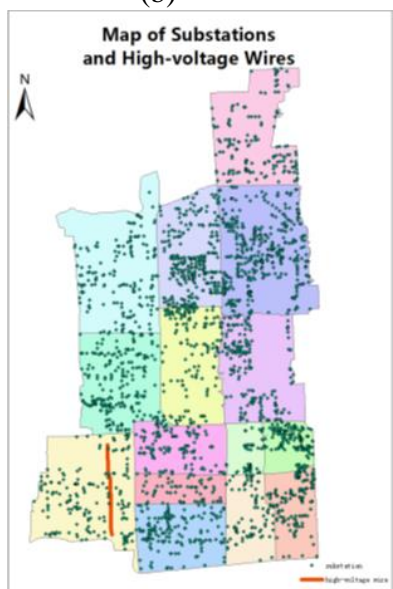

(d)
Figure 5. The initial data and the input parameters

Kernel density analysis is adopted to mainly monitor highdensity-population areas based on the rule b). Red area (Figure 6(a)) means the most aggregated population distributions, which are suitable to deploy rain gauges. According to the rule c) and d), a buffer zone map of roads with radiuses of $20 \mathrm{~m}, 30 \mathrm{~m}, 40 \mathrm{~m}$, $50 \mathrm{~m}, 60 \mathrm{~m}$ respectively, a buffer zone map of substations and high-voltage wires with radiuses of $10 \mathrm{~m}, 20 \mathrm{~m}, 30 \mathrm{~m}, 40 \mathrm{~m}, 50 \mathrm{~m}$, respectively are created. Those candidate sites located in the different buffer zones have different scores, namely, the closer distance is, higher the scores are. 


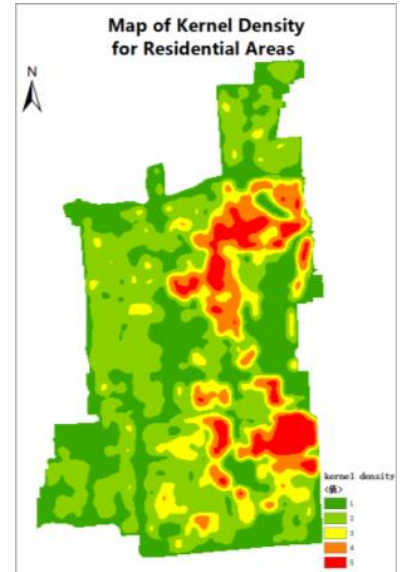

(a)

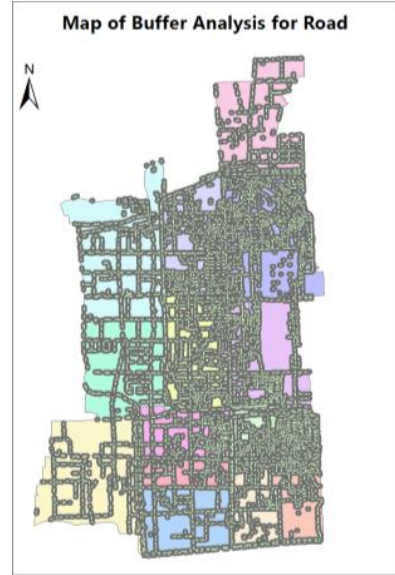

(b)

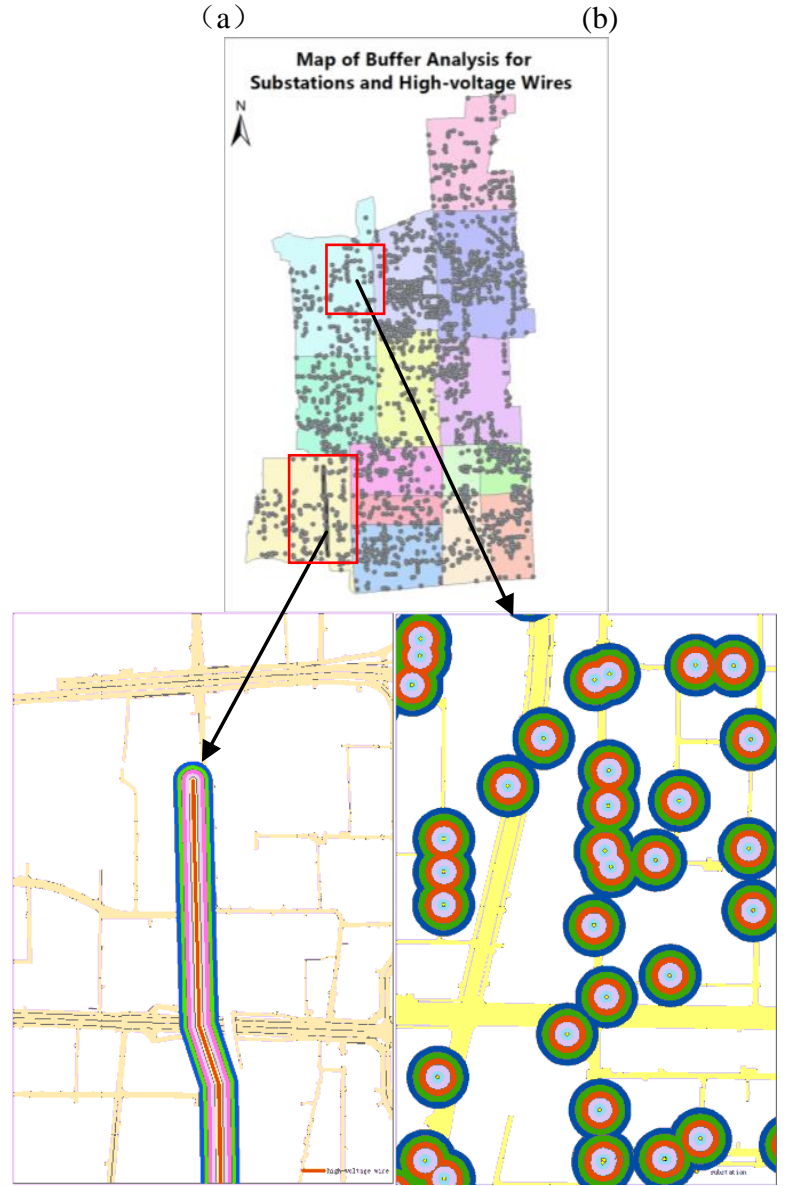

(c)

Figure 6. The initial data and the input parameters

The rain gauge site selection is calculated as below:

Rain gauge sites $=(\mathrm{S} 1 \times \mathrm{IR})+(\mathrm{S} 2 \times \mathrm{D} 1)+(\mathrm{S} 3 \times \mathrm{D} 2)+(\mathrm{S} 4 \times \mathrm{D} 3)(1)$

Among the formula (1), S1, S2, S3, S4 are the corresponding weights of rainfall interpolation, high-voltage wire, substation, and road. For calculating conveniently and simply, the weights are assigned in terms of numbers, from one to five, on account of relative codes, specifications and empirical analyses. IR derives from interpolation result of rainfall; D1 represents the distance from high-voltage wire; D2 stands for distance from substation; D3 is the Distance from the central line of road. Figure 7 (the left one) is the total scores calculated with the aid of the formulation (1). And then, the potential locations are identified into five levels using natural discontinuities classification method. Red point owns the lowest total scores, which means the position of the point is extremely unsuitable to site the rain gauge; the yellow point shows the less unsuitable position; the light green stands for the suitable location; the dark green is the less suitable one; and the dark blue demonstrates the most suitable site with the highest total score, which is the preferred position to install rain gauges. Figure 7 (the right one) is the final site-search (red triangle) for rain gauges based on the principle (b): the key monitoring, the uniform distribution.

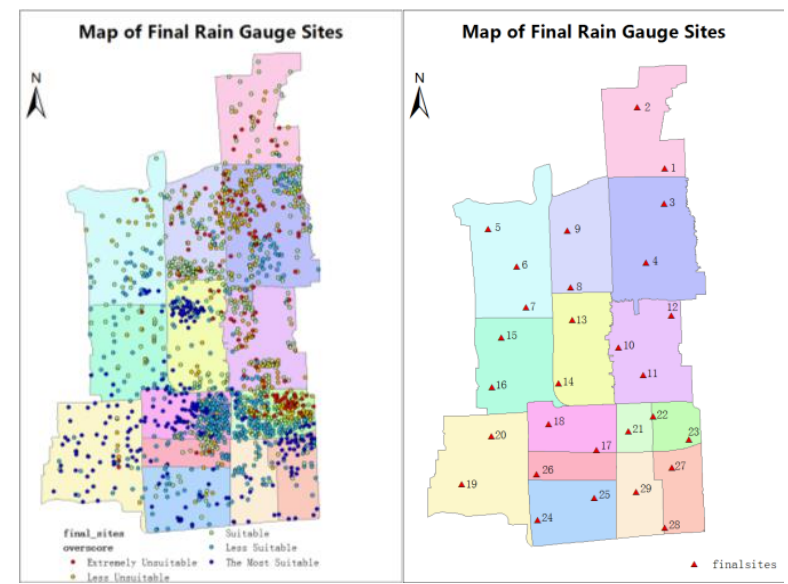

Figure 7. The distribution and number optimal point set

\section{DISCUSSION}

In traditional, site selection mainly relied on economic and technical criteria, almost with sparse distribution. Nowadays, density rain gauge monitoring network is urgently needed with development of economic and urbanization. Deployment feasibility, position, distance and spatial relationships with other geographic features are major considerations. The success of long-term rainfall monitoring with gauges depends on optimal siting of the rain gauges relative to a set of criteria. It is crucial to define a set of multicriteria for deployment of rain gauges. Therefore, this paper puts forward a novel approach for urban rain gauge site selection based on GIS-multicriteria analysis, which properly combines the advantages of GIS with multicriteria decision analysis. The result verified that the method is applicable to monitor small-scale city rainfall. The study was well applied to a project of monitoring precipitation in a regional area. Accurate rainfall monitoring data laid a solid foundation for city safe operation and citizens' personal safety. Under the complicated circumstance of a small-scale city, a series of criteria related to the study area were proposed. Aided by MCDA, the optimal sites can be obtained with the platform of GIS, which is beneficial to the local government financial resources. It is anticipated that adjusting some procedures, such as determining weights, will be very necessary to further optimize the rain gauges sites and provide ideas for other sitesearch requirements.

\section{References}

Anderson, T.K., 2009. Kernel density estimation and K-means clustering to profile road accident hotspots. Accident Analysis \& Prevention, Vol 41(3):pp. 359-364.

Arora, S. and Taylor, J.W., 2014. Forecasting electricity smart meter data using conditional kernel density estimation. Omega, Vol 59.

Bastin, G., Lorent, B., Duqué, C. and Gevers, M., 1984. 
Optimal Estimation of the Average Areal Rainfall and Optimal Selection of Rain Gauge Locations. Water Resources Research,Vol 20(20):pp. 463-470.

Borza, S. and Petrescu, V., 2016. The OLT River Pollution Monitoring, Using Spatial Analysis, Analityc Hierarchy Process And Technique For Order Preference By Similarity Methods. Process Safety \& Environmental Protection.

CARVER, S.J., 1991. Integrating multi-criteria evaluation with geographical information systems. Geographical Information Systems, Vol 5(3):pp. 321-339.

Church, R.L. and Li, W., 2015. Estimating spatial efficiency using cyber search, GIS, and spatial optimization: a case study of fire service deployment in Los Angeles County. International Journal of Geographical Information Science, Vol 30(3):pp. 119.

Comber, A., Dickie, J., Jarvis, C., Phillips, M. and Tansey, K., 2015. Locating bioenergy facilities using a modified GIS-based location - allocation-algorithm: Considering the spatial distribution of resource supply. Applied Energy, Vol 154:pp. 309-316.

Dyras, I. et al., 2003. The Use of Geographic Information Systems in Climatology and Meteorology, COST719. Meteorological Applications, $\mathrm{Vol}$ 27(3):pp. 313-330.

Fang, F., Xu, L., Can, L. and Zi-qian, X., 2014. Review of Spatial Multi-criteria Decision Making. Science of Surveying and Mapping, $\operatorname{Vol}$ 39(07).

García-Pintado, J., Barberá, G.G., Erena, M. and Castillo, V.M., 2009. Rainfall estimation by rain gauge-radar combination: A concurrent multiplicative-additive approach. Water Resources Research,Vol 45(45):pp. 206-218.

Geosciences, C.U.O., 2014. Review of spatial multi-criteria decision making. Science of Surveying \& Mapping .

Haberlandt, U., 2007. Geostatistical interpolation of hourly precipitation from rain gauges and radar for a large-scale extreme rainfall event. Journal of Hydrology, Vol 332(s 1 2):pp. 144-157.

Kar, A.K., Lohani, A.K., Goel, N.K. and Roy, G.P., 2015. Rain gauge network design for flood forecasting using multi-criteria decision analysis and clustering techniques in lower Mahanadi river basin, India. Journal of Hydrology Regional Studies, Vol 4:pp. 313-332.

Kloog, I., Haim, A. and Portnov, B.A., 2009. Using kernel density function as an urban analysis tool: Investigating the association between nightlight exposure and the incidence of breast cancer in Haifa, Israel. Computers Environment \& Urban Systems, Vol 33(1):pp. 55-63.

Lalita, Thakali, Kwon and Liping, 2015. Identification of crash hotspots using kernel density estimation and kriging methods: a comparison. Journal of Modern Transportation, Vol 23(2):pp. 93-106.

Leake, C. and Malczewski, J., 2000. GIS and Multicriteria Decision Analysis. Journal of the Operational Research Society, Vol 51(2).

Luciana Ansaneli, N., Lara Benigno, P., Rosa, J.O.W.C., Luiz
Augusto, C. and Rosa, J.W.C., 2015. Geographical information system (GIS) as a new tool to evaluate epidemiology based on spatial analysis and clinical outcomes in acromegaly. Pituitary, Vol 18(1):pp. 1-8.

Malczewski, J., 2007. GIS - based multicriteria decision analysis: a survey of the literature. International Journal of Geographical Information Science, Vol volume 20(20):pp. 703726.

Mishra, A.K. and Paulin, C., 2009. Developments in hydrometric network design: A review. Reviews of Geophysics, Vol 47(2):pp. 2415-2440.

Pardo-Igúzquiza, E., 1998. Optimal selection of number, location of rainfall gauges for areal rainfall estimation using geostatistics and simulated annealing. Journal of Hydrology, Vol 210(1):pp. 206-220.

R, E.J., 1999. Multi-criteria evaluation and GIS. Geographical information systems(1):pp. 493-502.

Sakai, N., Mohd, Y.R., Sapar, M., Yoneda, M. and Ali, M.M., 2016. Spatial analysis and source profiling of beta-agonists and sulfonamides in Langat River basin, Malaysia. Science of the Total Environment, Vol 548-549:pp. 43-50.

Shaghaghian, M.R. and Abedini, M.J., 2013. Rain gauge network design using coupled geostatistical and multivariate techniques. Scientia Iranica, Vol 20(2):pp. 259-269.

Shepherd, J.M., Taylor, O.O. and Garza, C., 2004. A Dynamic GIS Multicriteria Technique for Siting the NASA Clark Atlanta Urban Rain Gauge Network. Journal of Atmospheric \& Oceanic Technology, Vol 21(21):pp. 1346-1363.

Shi, X., 2010. Selection of bandwidth type and adjustment side in kernel density estimation over inhomogeneous backgrounds. International Journal of Geographical Information Science, $\mathrm{Vol}$ 24(5):pp. 643-660.

Su, H.T. and You, J.Y., 2014. Developing an entropy-based model of spatial information estimation and its application in the design of precipitation gauge networks. Journal of Hydrology, Vol 519:pp. 3316-3327.

Voogd, H., 1984. Multi-Criteria Evaluation for Urban and Regional Planning. Delftsche Uitgevers Maatschappij, Vol 21(4):pp. 473-474.

Wenhao, Y. and Tinghua, A., 2015. The Visualization and Analysis of POI Features under Network Space Supported by Kernel Density Estimation. (1):pp. 82-90..

Xiangnan, L., 2005. GIS Spatial Analysis Principle and Method.

Yiqiang, Y., Jinsong, G., Lingkui, M. and Shijun, D., 2007. Parallel Computing of Buffer Analysis Based On Grid Computing. Geospatial Information, Vol 1(5):pp. 98-101. 